\title{
Cholinergic stimulation with pyridostigmine reduces the QTC interval in coronary artery disease
}

\section{R.R.T. Castro ${ }^{1}$, \\ G. Porphirio ${ }^{3}$, \\ S.M. Serra ${ }^{3}$ and A.C.L. Nóbrega ${ }^{1,2}$}

\author{
${ }^{1}$ Departamento de Fisiologia e Farmacologia, and \\ 2Programa de Pós-Graduação em Cardiologia, \\ Universidade Federal Fluminense, Niterói, RJ, Brasil \\ Instituto Estadual de Cardiologia Aluísio de Castro, Rio de Janeiro, RJ, Brasil
}

\section{Correspondence}

A.C.L. Nóbrega

Rua Cinco de Julho, 318/1001

24220-111 Niterói, RJ

Brasil

Fax: + 55-21-2611-7059

E-mail: anobrega@ urbi.com.br

Research supported by CNPq

(No. 520660-95.1) and FAPERJ

(No. E-26/151.399/97).

Received November 8, 2001

Accepted April 1, 2002

\section{Abstract}

Parasympathetic dysfunction is an independent risk factor in patients with coronary artery disease; thus, cholinergic stimulation is a potential therapeutic measure that may be protective by acting on ventricular repolarization. The purpose of the present study was to determine the effects of pyridostigmine bromide (PYR), a reversible anticholinesterase agent, on the electrocardiographic variables, particularly QTc interval, in patients with stable coronary artery disease. In a randomized double-blind crossover placebo-controlled study, simultaneous 12-lead electrocardiographic tracings were obtained at rest from 10 patients with exercise-induced myocardial ischemia before and $2 \mathrm{~h}$ after the oral administration of $45 \mathrm{mg}$ PYR or placebo. PYR increased the RR intervals (pre: $921 \pm 27 \mathrm{~ms}$ vs post: $1127 \pm 37 \mathrm{~ms} ; \mathrm{P}<0.01$ ) and, in contrast with placebo, decreased the QTc interval (pre: $401 \pm 3 \mathrm{~ms}$ vs post: $382 \pm 3 \mathrm{~ms} ; \mathrm{P}<0.01$ ). No other electrocardiographic variables were modified (PR segment, QT interval, QT and QTc dispersions). Cholinergic stimulation with PYR caused bradycardia and reduced the QTc interval without important side effects in patients with coronary disease. These effects, if confirmed in studies over longer periods of administration, may suggest a cardioprotection by cholinergic stimulation with PYR.

\section{Introduction}

The impaired function of the autonomic nervous system increases the risk of arrhythmic events and sudden death after acute myocardial infarction (AMI) $(1,2)$. The early concept that adrenergic hyperactivity could be deleterious has led to the widespread clinical use of beta-blockers in patients after AMI, with a consequent reduction in overall mortality (3). Decreased parasympathetic ac-

\section{Key words}

- Pyridostigmine

- QTc interval

- Stable angina

- Anticholinesterase tivity also represents an independent risk factor in post-AMI patients $(4,5)$, but few studies have investigated the therapeutic options against parasympathetic dysfunction (6).

Ventricular repolarization (expressed by the QTc interval on the electrocardiogram) is of prognostic importance when evaluating post-AMI patients (7-10). In the present study we investigated the effect of pyridostigmine bromide, a reversible anticholinesterase 
agent, on the surface electrocardiogram of patients with stable angina.

\section{Material and Methods}

Ten patients with stable angina and exercise-induced myocardial ischemia, five of them with previous AMI (age: $64 \pm 9$ years; height: $163 \pm 8 \mathrm{~cm}$; weight: $73 \pm 10 \mathrm{~kg}$ ) gave written informed consent to participate in the study after full explanation of the procedures and potential risks. The study, in accordance with the Declaration of Helsinki, was approved by the Institutional Research Ethics Committee. A randomized cross-over and double-blind protocol was carried out on two separate days. An electrocardiogram (standard surface 12-lead simultaneous signal acquisition, ErgoPC ${ }^{\circledR}$ software, Micromed, Brasília, DF, Brazil) was recorded at rest in the supine position before and 120 min after the oral administration of $45 \mathrm{mg}$ of pyridostigmine bromide (Mestinon ${ }^{\circledR}$, Roche Pharmaceuticals, São Paulo, SP, Brazil) or placebo on each day. Each subject continued taking his/her usual medication throughout the study period. They were instructed to avoid alcohol, caffeine-containing beverages, and strenuous physical activity the day before the measurements.

The same observer, who was blind to the experimental condition, manually measured

Table 1. Electrocardiographic variables before (pre) and $2 \mathrm{~h}$ after (post) oral administration of placebo or $45 \mathrm{mg}$ pyridostigmine $(\mathrm{N}=10)$.

\begin{tabular}{|c|c|c|c|c|}
\hline \multirow[t]{2}{*}{ Variable } & \multicolumn{2}{|c|}{ Placebo } & \multicolumn{2}{|c|}{ Pyridostigmine } \\
\hline & Pre & Post & Pre & Post \\
\hline PR segment & $73 \pm 9$ & $73 \pm 8$ & $64 \pm 7$ & $69 \pm 7$ \\
\hline RR interval & $976 \pm 37$ & $1054 \pm 33^{*}$ & $921 \pm 27^{+}$ & $1127 \pm 37^{*+}$ \\
\hline QT interval & $392 \pm 8$ & $401 \pm 8$ & $386 \pm 9$ & $405 \pm 10$ \\
\hline QT dispersion & $58 \pm 5$ & $71 \pm 11$ & $73 \pm 3$ & $71 \pm 5$ \\
\hline QTc interval & $397 \pm 5$ & $392 \pm 6$ & $401 \pm 3$ & $382 \pm 3^{*}$ \\
\hline QTC dispersion & $56 \pm 6$ & $70 \pm 15$ & $70 \pm 8$ & $64 \pm 5$ \\
\hline
\end{tabular}

Data are reported as mean \pm SEM in $\mathrm{ms}$.

$* \mathrm{P}<0.01$ vs pre - same condition (ANOVA/t-test). ${ }^{+} \mathrm{P}=0.02$ vs placebo - same moment (ANOVA/t-test). the PR, RR and QT intervals over the 12 simultaneous electrocardiographic leads. The software enables enlargement of the electrocardiographic recordings, so that the measurement can be made with highest resolution.

The QT interval was measured from the beginning of the QRS complex to the end of the $\mathrm{T}$ wave where its hind limb joined the baseline. There were no $U$ waves in the traces analyzed. The QTc interval was obtained according to Bazett's formula (QT/ $\sqrt{\mathrm{RR})}$ (11), using the latest RR before the QT interval for calculation. Also, QT and QTc dispersions (maximum-minimum QT or QTc from the 12 simultaneous electrocardiographic leads, respectively) were derived. We used the mean value from the 12 leads for each variable (QT, QTc, RR intervals and PR segment) for analysis. The occurrence of adverse reactions was compared by the chi-square test. Each variable obtained from the electrocardiogram was analyzed by two-factor analysis of variance (ANOVA) with repeated measures where time (pre, post) and drug (pyridostigmine, placebo) were the main factors. If a significant $F$ value was obtained, ANOVA was followed by the Student-Newman-Keuls test for pairwise post hoc comparisons. Statistical significance was set at $\mathrm{P}<0.05$. Results are reported as mean \pm standard error.

\section{Results}

Pyridostigmine increased the duration of the RR intervals (Table 1). These increases corresponded to the following changes in heart rate: placebo - pre: $62 \pm 7 \mathrm{bpm}$, post: $57 \pm 7 \mathrm{bpm}$; pyridostigmine - pre: $65 \pm$ $6 \mathrm{bpm}$, post: $53 \pm 6 \mathrm{bpm}$. Pyridostigmine also reduced the QTc interval (Table 1; Figure 1). There was no difference between preand post-pyridostigmine or placebo values for PR interval, QT interval or QT and QTc dispersions (Table 1).

Pyridostigmine was well tolerated. Two 
subjects complained of mild headache and another subject reported abdominal discomfort after pyridostigmine, whereas one subject complained of headache and another presented with atrial tachycardia after placebo $(\mathrm{P}>0.05)$.

\section{Discussion}

Pyridostigmine exerts a vagomimetic action by inhibiting cholinesterase activity and increasing the concentration of acetylcholine in the synaptic cleft. It has been used extensively to counteract skeletal muscle weakness in patients with myasthenia gravis, but its cardiovascular action has been considered a side effect. Previous studies specifically investigating the hemodynamic changes induced by pyridostigmine have shown that a single dose of the drug decreases resting (12) and exercise (13) heart rate and reduces QTc dispersion (14) in healthy individuals without impairing exercise tolerance. When given at 8-h intervals, pyridostigmine elicited sustained 24- $h$ bradycardia and augmented heart rate variability (15). These effects were obtained without impairment of systolic or diastolic cardiac functions (16). In addition, a single $45 \mathrm{mg}$ dose of pyridostigmine given orally to healthy subjects blunted the double-product elevation during mental stress (17). Finally, pyridostigmine inhibited the hemodynamic response to central adrenergic stimulation produced by intracerebroventricular injection of glutamate in a rat model (18). The present study expands these previous findings demonstrating that a single oral dose (45 mg) of pyridostigmine causes bradycardia and reduces the QTc interval in patients with coronary disease, with only mild side effects.

These results may have important clinical implications. It is generally accepted that QTc prolongation occurs during the acute phase of AMI (7). Schwartz and Wolf (8) measured the QTc intervals on electrocardiograms taken every other month for seven years in survivors of AMI and found a constant QTc interval prolongation in those who died suddenly (2.16 times greater risk for sudden death). In addition, Ahnve et al. (9) assessed the first-year prognostic implications of the QTc interval by repeated measurements in survivors of AMI under 66 years of age. During the follow-up period, patients who suffered re-infarction or sudden death had significantly longer QTc values (434 \pm $35 \mathrm{~ms}$ vs $417 \pm 42 \mathrm{~ms}, \mathrm{P}<0.001)$. Also, they found a weak but significant correlation between QTc and left ventricular dysfunction at the time of discharge as well as one year later. Recently, Okin et al. (10) found that prolonged QTc is a significant predictor of all-cause mortality and cardiovascular mortality, even after multivariate Cox regression analyses controlling for other risk factors. Although these studies (7-10) have described a significant correlation between prolonged QTc and worse prognosis, they do not provide evidence that reducing the QTc interval, as occurs after pyridostigmine, would reduce morbidity or mortality of post-AMI patients.

A potential limitation of the present study refers to the fact that we have employed a single dose of pyridostigmine administered just once. Thus, further studies using prolonged administration of pyridostigmine are needed to determine whether QTc shortening

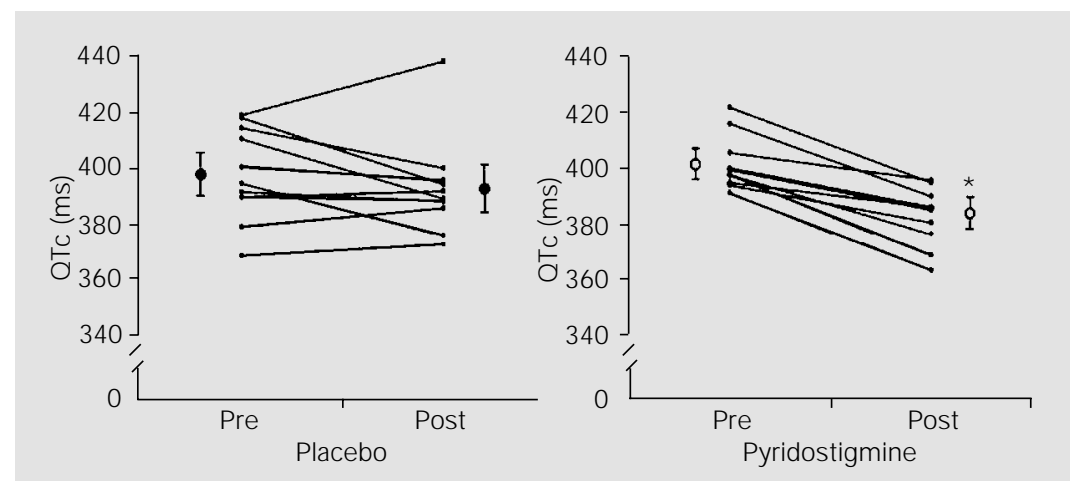

Figure 1. Individual values of QTc intervals before (pre) and $2 \mathrm{~h}$ after (post) oral administration of placebo or $45 \mathrm{mg}$ pyridostigmine on different days $(\mathrm{N}=10)$. The means and SEM for each group are also reported on both sides of the pre- and post-data. $* \mathrm{P}<0.01$ vs prepyridostigmine (ANOVA/t-test). 
will produce and sustain a protective effect.

Another issue is the use of Bazett's formula to calculate the QTc interval. There is a complex relationship between heart rate and the QT interval (19), making it impossible to propose a flawless method to correct the duration of ventricular repolarization for the underlying duration of the cardiac cycle. Some studies have investigated the relationship between parasympathetic stimulation and QT interval. Davidowski and Wolf (20) and Litovsky and Antzelevitch (21) concluded that vagal stimulation and acetylcholine prolong the QT interval independently of the bradycardia they induce. On the other hand, Cappato et al. (22) found that vagal tonus increased intrinsic QT dependence on diminishing heart rate. The results of another study (23) showed that rapid reflex parasympathetic stimulation does not influence QT interval duration or QT dispersion. Nevertheless, despite the limitations of Bazett's formula, all the studies investigating the prognostic value of the QTc interval have used it (7-10).

Pyridostigmine decreased resting heart rate and QTc interval. Although not directly investigated in the present study, it is possible that cholinergic stimulation, resulting in bradycardia and QTc reduction, protects the myocardium and decreases mortality in patients with coronary disease.

\section{References}

1. La Rovere MT, Bigger J J JT, Marcus FI, Mortara A \& Schwartz PJ (1998). Baroreflex sensitivity and heart-rate variability in prediction of total cardiac mortality after myocardial infarction. Lancet, 351: 478484.

2. Schwartz PJ, La Rovere MT \& Vanoli E (1992). Autonomic nervous system and sudden death. Experimental basis and clinical observations for post-myocardial infarction risk stratification. Circulation, 85 (Suppl I): I-77-I-99.

3. Bigger J T \& Coromilas J (1984). How do beta-blockers protect after myocardial infarction? Annals of Internal Medicine, 101: 256-258.

4. Kleiger RE, Miller JP, Bigger JTJ \& The Multicenter Post-Infarction Research Group (1987). Decreased heart rate variability and its association with increased mortality after acute myocardial infarction. American J ournal of Cardiology, 59: 256262.

5. Odemuyiwa O, Malik M, Farrell T, Bashir Y, Poloniecki J \& Camm J (1991). Comparison of the predictive characteristics of heart rate variability index and left ventricular ejection fraction for all-cause mortality, arrhythmic events and sudden death after acute myocardial infarction. American J oumal of Cardiology, 68: 434-439.

6. Nóbrega ACL \& Castro RRT (2000). Parasympathetic dysfunction as a risk factor in myocardial infarction: What is the treatment? American Heart J oumal, 140: e20.

7. Doroghazi RM \& Childers R (1978). Timerelated changes in the QT interval in acute myocardial infarction: possible relation to local hypocalcemy. American J ournal of Cardiology, 41: 684-688.

8. Schwartz PJ \& Wolf S (1978). QT interval prolongation as predictor of sudden death in patients with myocardial infarction. Circulation, 57: 1074-1077.

9. Ahnve $S$, Helmers $C$, Lundman $T$, Rehnqvist N \& Sjögren A (1980). QTc intervals in acute myocardial infarction: First-year prognostic implications. Clinical Cardiology, 3: 303-308.

10. Okin PM, Devereux RB, Howard BV, Fabsitz RR, Lee ET \& Welty TK (2000). Assessment of QT interval and QT dispersion for prediction of all-cause and cardiovascular mortality in American Indians The Strong Heart Study. Circulation, 101: 61-66.

11. Bazett HC (1997). An analysis of the timerelations of electrocardiograms. Annals of Noninvasive Electrocardiology, 2: 177194.

12. Nóbrega $A C L$, Carvalho ACG \& Bastos BG (1996). Resting and reflex heart rate responses during cholinergic stimulation with pyridostigmine in humans. Brazilian $J$ ournal of Medical and Biological Research, 29: 1461-1465.
13. Serra $S M$, Vivacqua $R$, Ramalho $S H R$, Santos KB, Bastos BG \& Nóbrega $A C L$ (2001). Exercise stress testing in healthy subjects during cholinergic stimulation after a single dose of pyridostigmine. Arquivos Brasileiros de Cardiologia, 76: 279284.

14. Castro RRT, Serra SM \& Nóbrega $A C L$ (2000). Reduction of QTc interval dispersion. Potential mechanism of cardiac protection of pyridostigmine bromide. Arquivos Brasileiros de Cardiologia, 75: 210213.

15. Nóbrega $A C L$, Reis $A F$, Moraes RS Bastos BG, Ferlin EL \& Ribeiro J P (2001). Enhancement of heart rate variability during cholinergic stimulation with pyridostigmine in healthy subjects. Clinical Autonomic Research, 11: 11-17.

16. Pontes PV, Nóbrega ACL, Mesquita ET, Bastos BG, Carvalho ACG \& Romêo LJ M (1999). Cholinergic stimulation with pyridostigmine, hemodynamic and echocardiographic analysis in healthy subjects. Arquivos Brasileiros de Cardiologia, 72: 302306.

17. Nóbrega $A C L$, Carvalho ACG, Santos KB $\&$ Soares PPS (1999). Cholinergic stimulation with pyridostigmine blunts the cardiac responses to mental stress. Clinical Autonomic Research, 9: 1-6.

18. Grabe-Guimarães A, Alves LM, Tibiriçá $E$ \& Nóbrega ACL (1999). Pyridostigmine 
blunts the increases in myocardial oxygen demand elicited by the stimulation of the central nervous system in anesthetized rats. Clinical Autonomic Research, 9: 8389.

19. Funck-Brentano C \& J aillon $P$ (1993). Ratecorrected QT interval: Techniques and limitations. American J ournal of Cardiology, 72: 17B-22B.

20. Davidowski TA \& Wolf S (1984). The QT interval during reflex cardiovascular adaptation. Circulation, 69: 22-25.

21. Litovsky SH \& Antzelevitch C (1990). Differences in the electrophysiological response of canine ventricular subendocardium and subepicardium to acetylcholine and isoproterenol. A direct effect of acetylcholine in ventricular myocardium. Circulation Research, 67: 615-627.

22. Cappato R, Alboni P, Pedroni P, Gilli G \&
Antonioli GE (1991). Sympathetic and vagal influences on rate-dependent changes of QT interval in healthy subjects. American J oumal of Cardiology, 68: 1188-1193.

23. Kautzner J, Hartikainen J E, Heald S, Camm AJ \& Malik M (1997). The effects of reflex parasympathetic stimulation on the QT interval and QT dispersion. American J oumal of Cardiology, 80: 1229-1232. 